\title{
The Profit and Non-Profit Value Selection of Special Legislation in Chinese Kindergartens
}

\author{
Gui-Lin GAO ${ }^{1}$, Yu-Yu HAN ${ }^{2, *}$ \\ ${ }^{1}$ School of Law professor, Capital University of Economics and Business, China \\ ${ }^{2}$ School of Law student, Capital University of Economics and Business, China

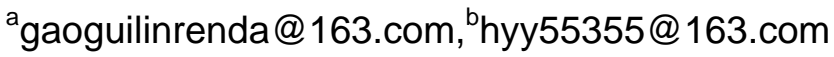

Keywords: Non-profit, Private Kindergarten, Preschool education, Market access.

\begin{abstract}
This paper starts with the basic idea of economic law based on the maintenance of social and public interests, argues that the development of private kindergartens to promote the development of pre-school education and to meet the diversification of education in pre-school is of great importance. While supporting the development of private education, private kindergartens, as an important carrier of preschool education, should take non-profit as the purpose to achieve their public welfare. Due to the existence of non-standard and profit-driven problems in private kindergartens, the government's guidance and supervision on kindergartens are not in place, the laws and regulations are lagging behind, the organizers do not have the sense of reasonable profit making, the legitimacy of the profit making behavior in private kindergartens can not be effectively supervised. Therefore, it is not suitable for the purpose of making profit. Drawing on the legislative practice of the private kindergartens in Taiwan and Japan, government's award and supervision to private kindergartens can be strengthened in our country by strengthening the special legislation of preschool education, and stipulate the reasonable return of the private kindergartens, and establish a perfect non-profit private kindergarten market access, operation, supervision and withdraw mechanism, to clarify the responsibilities of the government, increase the financial support for education, and to support the poor and remote areas to realize the non-profit purpose of private kindergartens.
\end{abstract}

\section{Introduction}

Education, as a fundamental task crucial for generations to come, pre-school education is a basic stage for the development of individuals and plays a key role in development of personal and mental health. The number of private kindergartens in China accounts $64.3 \%$ of the total number of kindergartens. As an important carrier of preschool education, in the market at the same time, private kindergartens should exist in the identity of the enterprise to pursue market interests, or to maintain social interests as the starting point to shoulder more social responsibilities, for the purpose of non-profit, to realize the public welfare of public education, the so-called "public welfare" means that preschool education can bring economic and non-economic benefits to other members of school-age children (and their immediate family members), and this education income is for the majority or even of all citizens without exclusive access. There are different opinions on this in society.

\section{The Value Game between the Profit and the Non Profit of the Private Kindergarten}

\section{Private Kindergartens can have the Purpose of Profit - Making}

On the one hand, as enterprises, the goal of private kindergartens is the pursuit of profit maximization; it should be based on making profit purpose. On the other hand, the provisions of the nineteenth article of the law of promoting the promotion of private education in People's Republic of China, "The owners of private schools can choose to establish non-profit or profit - run private schools independently, however, setting up for-profit private schools that carry out compulsory 
education is not allowed", which was fully implemented on September 1, 2017. But according to the provisions of the Law of the People's Republic of China on Compulsory Education, "for children who has reached the age of six, their parents or other legal guardians should send them for admission and complete compulsory education; children in areas where conditions are not available can be delayed until the age of seven." And it stipulates, "The state carries out the nine year compulsory education system.” In other words, education before the age of 6 does not belong to the category of compulsory education. The organizers of private schools can set up profitable kindergartens by themselves, which can be profitable. The "traditional company law theory" think company as purely for-profit economic organization, profit as much as possible so as to realize maximize the profit of shareholders is the highest and ultimate goal of the company, it is believed that the ultimate goal of the enterprise lies in the interest, not the responsibility, and the company's responsibility is strongly denied.

\section{Private Kindergartens should Take Non - Profit as the Purpose}

It is stipulated in article 25 of Law of the People's Republic of China on Education, "The state has formulated educational development plans and held schools and other educational institutions. The state encourages enterprises, institutions, social organizations, other social organizations and citizens to hold schools and other education institutions in accordance with law. No organization or individual shall hold schools and other educational institutions for the purpose of making profit." The law stipulates that the organization of schools and educational institutions shall not be for-profit.

In recent years, we have been emphasizing the market economy, and some people have put forward and practiced the marketing operation and industrialization operation into education field. But as an important point of support for the national strategy of rejuvenating the country by science and education, education should also be of the nature of public welfare. It is an important complement to national public goods and should not be a substitute for benefit and profit.

\section{The Main Cause of the Value Game}

\section{The Legislation of Private Preschool Education is not Perfect Enough}

There are contradictions in the provisions of Law of the People's Republic of China on Education and the law of promoting the promotion of private education in People's Republic of China on the relevant provisions of private preschool education, and there is still a large number, significant omissions, omissions, or problems in the existing laws and regulations. According to the provisions of article 19 of The law of promoting private education, the owners of private kindergartens may make profit for its purpose, but according to the provisions of article 25 of Law of the People's Republic of China on Education, the establishment of schools and other educational institutions shall not be for profit - making purposes, and the establishment of private kindergartens should not be made for profit - making purposes, therefore, the private kindergartens play a game between profit and non-profit value choice.

\section{Lack of High Level Legislation for the Preschool Education}

The relevant provisions on preschool education are scattered in various educational laws and regulations. It is stipulated in article 17 of Law of the People's Republic of China on Education, "The State implements the school education system of preschool education, primary education, secondary education and higher education." In the prescribed four independent stages of study, China has promulgated The law of higher education in People's Republic of China, Law of the People's Republic of China on Compulsory Education, Law of the People's Republic of China on Teachers and Law of the People's Republic of China on Vocational Education and so on, but there is no high level legislation for pre-school education. At present, the management of preschool education in China is mainly based on the regulations of regulations on the management of kindergartens and Work rules for kindergartens; the legislation level of preschool education is low, 
the lack of high-level legal system leads the lack of legal basis for solving all kinds of preschool education problems, there is no clear nature and value orientation of private kindergartens.

\section{There Exist Conflict between the Public Welfare of Preschool Education and the Profit of the Enterprise}

The purpose of private kindergartens as enterprises is to pursue the maximization of interests, but private kindergartens, as the education business, are vital to the development of the individual and the whole society, to adhere to the nature of its public welfare is to be responsible for the society and actively undertake the performance of social responsibility. There is conflict between the public welfare of the pre-school education and the interests of enterprises; the pre-school education will cause market failure due to the lack of market and government in the supply process.

\section{Private Kindergartens should be Selected for Non-Profit Value Purpose}

\section{The Purpose of Making Profit is not Conducive to the Healthy Development of Education}

The following four characteristics of private kindergartens for the purpose of profit making in China are bound to cause the phenomenon of "arbitrary charging", which generally affects social equity and is not conducive to the healthy development of education.

First of all, the number and proportion of private kindergartens in China is large. According to the statistics provided by Statistical bulletin on national educational development and development in 2015: by the end of 2016, the number of private kindergartens accounted for $64.3 \%$ of the total number of kindergartens in the country, The number of private kindergartens accounts for a large proportion of the number of kindergartens in China, the number of children in kindergartens in kindergartens in private kindergartens exceeds $50 \%$ of the total number of children in kindergartens in the country, it can be seen private kindergartens play an important role in preschool education in China. When the education institution, which accounts for such a large proportion, becomes a money-making machine, then the harm is the interests of the whole society, and the gap between the public kindergartens and the private kindergartens is constantly widened, and the social unfairness is caused.

Secondly, private kindergartens are in short supply. In 2016, the gross admission rate of preschool education in China reached $77.4 \%$, due to the restriction of educational resources; some children in our country still can't accept preschool education, especially those in poor and remote areas. If the private kindergartens are for profit, the current situation of the education market supply is a prerequisite for the maximization of the benefits of the holding of kindergartens. Parents will not pay much attention to the reasonableness of fees for their children's learning. From the perspective of educational resource allocation, it will further widen the phenomenon of uneven distribution of preschool education resources among regions.

Thirdly, the investment subject is single, the government financial award is less, and the parents pay the high cost. Since private kindergartens have a single investment, the expenditure of various funds only comes from the sponsor's investment and childcare expenses, the "cake" which is divided by government finance to private kindergartens is less, in order to save cost and due to the attraction of profit, many private kindergartens will cut down the funds to improve the funding for the garden, and try various ways to charge parents. Under such background, if private kindergartens are still aiming at making profits, private kindergartens will be a profitable, brightly colored "arbitrary charging" institution, which will increase the parents' financial burden.

Fourthly, government has poor supervision. The number of kindergartens has risen sharply, the quality of running a school is uneven, and there are many problems, such as the unlicensed garden, and other problems. The national legislation of preschool education is not perfect, and the legal system related to the market access, market operation, market regulation and market supervision of non-profit kindergartens is not perfect, the lack of government regulation makes the kindergarten in a state of running without management. The disorderly charge behavior of the private kindergartens 
is indulged and the rights of the masses are hurt, and the crisis of trust in private kindergartens has emerged.

To sum up, such as: the problem of non-standard and profit-driven kindergarten is still outstanding, the government's guidance and supervision of kindergartens are not in place, and the legal norms lag behind, the host lacks reasonable profit consciousness, the government lacks the supervision of reasonable profit, the purpose of private kindergartens for profit - making will make education exclusivity and destroy the principle of public welfare in education, it will also threaten the rights of consumers.

\section{The Rationality of Value Choice with Non-Profit Purpose}

Firstly, preschool education plays an important role in individual development. Studies have found that children are very malleable in the first few years, and if they have a defect, they can make up for it; the loss of the best opportunity for compensation will be a lifetime regret, and the cost of remedies will be quite expensive and even impossible to make up for. Because preschool education plays an important role in the enlightenment and development of individuals, it must be emphasized that the market should not regulate its public welfare. We allow private education enterprises to have the right to pursue reasonable rewards, but this right should also be determined while maintaining the overall interests and utility of the society. But one cannot enlarge the "enterprise nature" of private education enterprises, and pursue the maximization of their own interests; instead one should have the concept of value judgment for the social responsibility of the enterprise under the premise of social standard.

Secondly, education is a service that can't be seen and can't be touched; the influence on people is imperceptible. The higher the age of education is, the higher the recognition of the product, the lower the unreliability runs by the profit - making company. The object of education in kindergartens is generally less than 6 years old, with low recognition ability and weak judgment ability. Parents cannot always accompany in kindergartens, so the quality of education is very hard to evaluate for consumers. And the premise of the market transaction should be the products that the buyers and sellers can measure, there exist information asymmetry in the transaction process, if the private kindergartens are for the purpose of profit making, it will certainly help the profit - making kindergarten break the moral bottom line in the process of competition, to put more energy into marketing and fraud, resulting in unfair and unfair inequity in market transactions, which hurts consumers. Therefore, private kindergartens should be non-profit oriented.

\section{The Legislative Practice of Private Kindergartens in Taiwan and Japan in Order to Achieve the Purpose of Non Profit}

\section{Taiwan}

As early as 1981, Preschool education law has been introduced in Taiwan , the division of public kindergartens and private kindergartens clearly defines the legal status of private kindergartens, among them, the fees, education goals, purpose, setting standards and punishment measures for private kindergartens are strictly regulated to ensure the realization of the public welfare purpose of private kindergartens. The administrative authorities have approved the charge to reduce the phenomenon of "disorderly charge", provisions for punishing unlicensed gardens; it is a wake-up call for the organizers. In 2000, Taiwan promulgated Law of educational budget allocation and management, it is stipulated that the government's budget for education funds cannot be less than $21.5 \%$ of the average net income of the final accounts in the first three years of the budget, it provides adequate financial support for the development of education in Taiwan, and realizes the public welfare of education. In 2011, Children's education and care law was introduced in the Taiwan region, more detailed and in-depth regulations have been made for the development of private kindergartens, which replaced Preschool education law, it provides a new legal basis for the study of the establishment and operation of private kindergartens, according to the inadequacies in 
reality, the legal system of preschool education is constantly improved.

Taiwan has basically formed the basis of Fundamental Law of Education, with Children's education and cares law and The Private School Law as the main pillar, Law of educational budget allocation and management, Teacher Law as important supplement of the Constitution and the legal system of private preschool education. In 2017,the Ministry of education of our country writes, "starting the legislation of the Pre-school Education Law" in the main points of work. However, in the face of the lack of legislation in preschool education, the current situation of the imperfect legal system of preschool education, there is always a lack of compulsory guarantee for the expenditure of education, in the process of legislation, China can learn from Taiwan's legislative experience and improve the legal system of pre-school education, pay attention to the regulation and management of private kindergartens and provide institutional guarantee for the non-profit goal of private children, and strengthen the government's financial assistance to promote the healthy development of private kindergartens.

\section{Japan}

Japan's legislation on private preschool education began early, as early as 1949; The Private School Law, The private school law order and Rules for the implementation of private school law were enacted. In the course of the development of private kindergartens in Japan, the central and local financial appropriations were mainly used for public preschool education institutions, the cost pressure of education for the parents of private kindergartens was very high, and the lack of funds resulted in poor conditions for the establishment of the park. The poor quality of teachers bred all kinds of undesirable social phenomena. In order to further realize the public welfare of private kindergartens, the Japanese government issued a series of decrees: Private school staff assemblage law, Private school rejuvenation of the consortium law, Private school revitalization of the financing law, Private school revitalization of the financing law enforcement Order, and Legal person law of the school and so on. To increase the investment in the education of private kindergartens, a series of award mechanisms have been set up to provide a good financial support for the development of private kindergartens.

\section{Legislative Proposals for Non-Profit Purpose of Private Kindergartens in China}

\section{Speeding Up the Special Legislation of Preschool Education and Perfecting the Legal System of Private Preschool Education}

The legislation of preschool education embodies the government's importance to preschool education; it is common practice in many countries to promote the development of private preschool education through legislation. Under the background of the full implementation of the two-child policy in our country now, in 2016, there were 17.86 million births nationwide, it has increased 1.31 million people in 2015 and with the highest growth rate of birth since 2011, this means that more and more children will need to receive pre-school education, which needs the protection of the law, and needs the government's attention and help. Only the laws and regulations such as the law of promoting private education, Regulations on the management of kindergartens cannot solve the problems that have ensued in the reality. There are many problems such as unlicensed kindergarten, unreasonable fees, etc., which have caused wide public concern, and has led many parents to reduce their trust in the pre-school education, only through high level legislation can define the status, nature, objective and purpose of the education system in our country; to clarify the functions and responsibilities of government in pre-school education; to make clear the standards for the holding and approval of private kindergartens; clear teacher's eligibility and guarantee; the mechanism of supervision and punishment for private kindergartens shall be clearly defined; to eliminate the for-profit behavior of private kindergartens and to realize the rule of law in accordance with the law. Therefore, it is the requirement of the times and the requirement of the people's livelihood to speed up the legislative process of preschool education and to clarify 
the non-profit nature of the private kindergartens. In addition, it is also necessary to improve the existing private preschool education system in a timely manner, to solve the conflicts and contradictions existing in the existing system, make clear regulations on the examination and approval standards of the private kindergartens and the funds guarantee. A perfect private preschool education legal system based on the preschool education law is formed to promote the healthy development of the kindergarten and realize its public welfare goal.

\section{Improve Market Access, Operation, Supervision and Exit Regulation and Clear Government Responsibilities}

It is impossible to realize the non-profit of the private kindergarten by the strength of the market alone; it is necessary to use the power of the government. To clarify the government's responsibilities and supervision and management of private kindergartens, it is necessary to improve the market access, operation, and supervision and withdrawal mechanism of private kindergartens.

The establishment of a non-profit private kindergarten market access system is the starting point for the government to perform its duties, non-profit private kindergarten market access system for non-profit private kindergarten should have capital, sites, scale, teachers' qualification, the articles of association of the kindergarten, organization, and the examination and approval, registration and other legal conditions and legal procedures are clearly defined; clearly defined institutions and duties for examination and approval and registration; clear examination and approval procedures and their duration; in view of the phenomenon of the interests of the sponsor and the examination and approval department of the private kindergartens, the establishment of the avoidance and the public procedure system should be jointly supervised by the social subject; it provides a remedy for private kindergartens that have not permitted access to the market, and protects their legitimate rights while preventing the authorities from abusing their functions and powers.

Improving the market operation system of non-profit private kindergartens, the government charge classified pricing for private kindergartens according to the principle of fairness and honesty and credit; the non-profit private kindergartens should carry out the public system of the detailed list of educational expenses and show the amount and direction of their educational expenditure to the parents; the mechanism of the communication between parents and kindergartens will be established to increase the number of exchanges, so that the government supervision and the supervision of the masses will be carried out to the maximum extent to prevent the frequent occurrence of "unreasonable charges"; to construct the mechanism of the flow and sharing of teachers and establish the education cooperation mechanism, encourage the teachers of private kindergartens to learn from each other, improve education level and strengthen the faculty. Finally, the education service mechanism of government, market and social consultation and co governance should be formed, so as to ensure the effectiveness of the operation of private kindergartens.

The key to the construction of the non-profit private kindergarten market supervision system is to rationally deal with the relationship between the nature of the market main body and the non - profit of education, internal supervision should be carried out in parallel with external supervision. For internal supervision, one is to build a perfect internal supervision of the staff and workers, to establish a staff representative assembly or to hold the inspection activities during the period of work, supervise each other and make progress together; the other one is to improve the supervision mechanism of financial accounting, through a strict budgeting system, the financial statement disclosure system discloses the expenditure of education cost and the income of senior management personnel, so as to strengthen the control of the income and expenditure of private kindergartens. For external supervision, one is to make clear the responsibilities of the industry authorities, increase the punishment of illegal private kindergartens, and realize the credibility of the government and the deterrence of the law; second is to build a reasonable evaluation mechanism, have a comprehensive assessment of the financial situation, the level of teachers and the quality of work, the comprehensive performance and the social responsibility of non-profit private kindergartens, so as to provide the basis for supervision. 
The market withdrawal of non-profit private kindergartens including voluntary withdrawal from the market and mandatory withdrawal, to establish a virtuous circle of non-profit private kindergarten system, it is necessary to combine the market access system with the market withdrawal system to establish the perfect non-profit private kindergarten withdrawal mechanism. The provisions of the whole process of withdrawal "decision - notice - liquidation - cancellation", build an auxiliary mechanism for the withdrawal of non-profit private kindergartens. First, the evaluation system of non-profit private kindergartens is implemented; the non-profit-making private kindergartens and staff members who do not meet the requirements will be adjusted and refunded in a timely manner to ensure the quality of pre-school education. Secondly, non-profit private kindergartens after the law is liquidated in accordance with the law, for the part of its asset appreciation, it should be incorporated into the local government's special funds for the development of preschool education in the form of donations, after the approval of the relevant financial departments, a corresponding proportion of one-time awards may be given to the owners of non-profit private kindergartens.

\section{Grade Pricing and Award the Charging Standard of Private Kindergartens}

Private kindergartens can meet the needs of diversified preschool education, however preschool education as an important stage of education, private kindergarten should not be put into the market, adjust its price by market as an important stage of education, the government can set up grading standards according to the area of the private kindergartens, the conditions of running the garden and the level of teachers, grade pricing for different classes of kindergartens, prevent of disorderly charge in private kindergartens to realizing its non profit purpose.

Over the years, the financial input of Chinese preschool education has been well below the international level, the lack of financial input in preschool education seriously restricts the development of preschool education. Taiwan and Japan have issued a series of financial support and awarding system for private preschool education institutions, provide adequate financial support for the healthy development of private kindergartens and provide a source for the improvement of the condition of the park. China should also establish a financial subsidy mechanism for private kindergartens: first, to non-profit private kindergartens organizer who has self built room or rental house, when the number of people entering the park reaches a certain standard of award, those who pass the acceptance inspection shall receive the award according to the corresponding standards; second, awards for organizers and teachers in the remote and poverty-stricken areas of the establishment of non-profit private kindergartens; third, formulate tax relief policies according to different circumstances; fourth, mandatory provisions on expenditure and budgets of funds, formulate financial expenditure and budget standards to provide a sufficient and reasonable material basis for the healthy development of private kindergartens to achieve non-profit purposes. While implementing various preferential policies, to strengthen the government supervision and management of private kindergartens and the guidance function, reward and punishment with distinction, avoid all kinds of fish in troubled waters, corner-cutting events happening.

\section{Increase the Support for Non-Profit Private Kindergartens in Poor Areas}

At present, China's pre-school education resources are not evenly distributed, the gap between urban and rural areas is too large and the regional gap is also too large, because of the lack of education resources and the weak foundation of the material economy, many rural children are unable to receive pre-school education, governments at all levels should make statistics on the number of young children in their areas and the trend of change, and take a holistic approach to the needs of pre-school education, Formulating different support policies, formulating scientific development plan and rationally adjusting the dualistic structure of preschool education in urban and rural areas, increase policy support for kindergartens, weak kindergartens, rural remote area kindergarten, migrant children kindergarten' ensure preferential treatment for the construction funds, education facilities, teachers' treatment and teacher training for non-profit private kindergartens, not only are tax exemptions implemented, but they can also be rewarded with spiritual and material 
rewards for the successful organizers and teachers, to promote the development of non-profit private kindergartens in poor areas and reduce regional differences, make every child has the right to receive preschool education.

\section{Conclusion}

Education is the foundation of a country, and young children are the hope of the future, as the important stage of education, education should have the essence of education public welfare, private kindergartens as an important carrier of education, should not have the purpose for profit. It is possible to improve the existing laws and regulations by strengthening the special legislation of the former education, establishing a perfect non-profit private kindergarten market access, operation, supervision and withdraw mechanism, clear the responsibility of the government, increase financial support for education and support in the remote areas of poverty, to achieve the non-profit goal of private kindergartens. The quality of the private kindergartens in China is uneven because the proportion is huge; achieving a nonprofit is a long and difficult process, it is a long way to go and is a tremendous task.

\section{Reference}

[1]Gao Lanjun etc. 2011. Legal Research on corporate social responsibility in the perspective of Globalization [M]. Beijing: Law Press.P14.(In Chinese)

[2] Wang Peng, Wang Jing.2012. The value orientation of private education enterprises - from the perspective of corporate social responsibility[J].Journal of Yunnan University (Law Edition). P25(02):128-131.(In Chinese)

[3] Wu Libao. 2003.The experience and enlightenment of the development of private preschool education in Japan[J].Studies in Preschool Education. P(04):59-60.(In Chinese)

[4]Pang Lijuan, Xia Jing, Sha Li. 2013.The experience and enlightenment of promoting the healthy development of private preschool education in Taiwan District legislation[J].Education Science.P29(01):88-93.(In Chinese)

[5]Meng Qingyan. 2008.The development and Enlightenment of Japanese preschool education under World War II laws and regulations[J].Contemporary preschool education. P(06):44-48.(In Chinese)

[6]Song Lihui. 2016.The legal regulation of preschool education in China[J].Hebei Law Science. P34(12):155-167.(In Chinese)

[7]Liu Hongchang, Xu Jianping. 2011.The public welfare of the preschool education in China from the perspective of government responsibility[J].Studies in Preschool Education. P(02):3-7.(In Chinese)

[8] Guo Lei. 2013.The mechanism, Predicament and Countermeasures of non-profit private preschool education organization development [J]. P34(03):35-40.(In Chinese)

[9] Liu Zhanlan. 2009.Education and public welfare must be maintained in preschool education[J]. P30(05):31-36.(In Chinese)

[10]Liu Hongchang, Xu Jianping. 2011.The public welfare of the preschool education in China from the perspective of government responsibility [J]. Studies in Preschool Education. P(02):3-7.(In Chinese) 